\title{
OPEN Drug-drug interactions in atrial fibrillation patients receiving direct oral anticoagulants
}

\author{
JiYun Lee ${ }^{1}$, Il-Young Oh ${ }^{1}$, Ju-Hyeon Lee ${ }^{1}$, Seok Kim², Jihoon $\mathrm{Cho}^{2}$, Charg Hyun Park², \\ Sooyoung Yoo ${ }^{2} \&$ Soo-Mee Bang ${ }^{1 \bowtie}$
}

Polypharmacy is common in patients with atrial fibrillation (AF), making these patients vulnerable to the occurrence of potential drug-drug interactions (DDIs). We assessed the risk of ischemic stroke and major bleeding in the context of concomitant treatment with potential DDIs in patients with AF prescribed direct oral anticoagulants (DOACs). Using the common data model (CDM) based on an electronic health record (EHR) database, we included new users of DOACs from among patients treated for AF between January 2014 and December $2017(n=1938)$. The median age was 72 years, and $61.8 \%$ of the patients were males, with $28.2 \%$ of the patients having a $\mathrm{CHA}_{2} \mathrm{DS}_{2}-\mathrm{VASc}$ score in category $0-1,49.4 \%$ in category $2-3$, and $22.4 \%$ in category $\geq 4$. The $\mathrm{CHA}_{2} \mathrm{DS}_{2}-\mathrm{VASc}$ score was significantly associated with ischemic stroke occurrence and hospitalization for major bleeding. Multiple logistic regression analysis showed that increased risk of ischemic stroke and hospitalization for major bleeding was associated with the number of DDIs regardless of comorbidities: $\geq 2$ DDIs was associated with ischemic stroke $(\mathrm{OR}=18.68 ; 95 \% \mathrm{Cl}, 6.22-55.27, P<0.001)$ and hospitalization for major bleeding $(O R=5.01 ; 95 \% \mathrm{Cl}, 1.11-16.62, P<0.001)$. DDIs can cause reduced antithrombotic efficacy or increased risk of bleeding in AF patients prescribed DOACs.

Atrial fibrillation (AF) is a major public health burden worldwide, and the prevalence of AF is remarkably increasing according to population aging ${ }^{1,2}$. AF increases the risk of ischemic stroke by nearly fivefold and accounts for up to $15 \%$ of strokes in people of all ages and $30 \%$ in people over the age of 80 years ${ }^{3,4}$. Direct oral anticoagulants (DOACs), including dabigatran, rivaroxaban, apixaban, and edoxaban, are being increasingly prescribed in clinical practice as the preferred class of oral anticoagulants for stroke prevention in non-valvular AF ${ }^{5-9}$. Although DOACs represent an advance in therapeutic safety when compared to warfarin for the prevention of stroke, the appropriateness and accuracy of prescribing medications are important ${ }^{10,11}$.

Drug-drug interactions (DDIs) are a concern for both patients and providers, as polypharmacy is becoming more common in managing complex diseases or comorbidities ${ }^{12}$. Among AF patients included in recent clinical trials, the prevalence of polypharmacy ranged between 40 and $75 \%$ and was linked to increased rates of cardiovascular mortality, bleeding, and thromboembolic complications ${ }^{13-15}$. Recently, data on DDIs with DOACs and increased risk of bleeding have emerged from large claims database studies ${ }^{16,17}$. Momo et al. showed that both the pharmacokinetics and the pharmacodynamics of DDIs increased the risk of bleeding in AF patients receiving anticoagulants by about 7 -fold ${ }^{16}$. Our group reported an approximately fourfold increase in risk for major bleeding events in DOAC users concomitantly taking $\geq 2$ potentially interacting drugs, regardless of comorbidities ${ }^{17}$.

The Observational Health Data Sciences and Informatics (OHDSI) is an international collaborative organization whose goal is to create and apply open-source data analytic solutions to a large network of health databases ${ }^{18}$. OHDSI adopts a distributed research network with the Observational Medical Outcomes Partnership Common Data Model (OMOP-CDM), which allows for the systematic analysis of disparate observational databases for clinical research ${ }^{19}$. Recent studies demonstrated that the use of OMOP-CDM was feasible for pharmacoepidemiologic and pharmacovigilance research ${ }^{20,21}$.

The purpose of this study was to assess whether potential DDIs affect the safety and efficacy of DOACs in patients with AF using a CDM at a single institution.

\footnotetext{
${ }^{1}$ Department of Internal Medicine, Seoul National University Bundang Hospital, Gumi-ro 173 Beon-gil, Bundang-gu, Seongnam-Si 13620, Gyeonggi-di, Republic of Korea. ${ }^{2}$ Office of eHealth Research and Business, Seoul National University Bundang Hospital, Seongnam, Republic of Korea. ${ }^{\circledR}$ email: smbang7@snu.ac.kr
} 


\section{Methods}

Data sources. Electronic health records (EHRs) data from Seoul National University Bundang Hospital were transformed into OMOP-CDM version 5.2. Diagnoses were coded according to the 6th Korean Classification of Disease modified classification systems from the International Classification of Disease-10 (ICD-10). Drug names were mapped to the Anatomical Therapeutic Chemical Classification System.

This study was performed in accordance with the Declaration of Helsinki and approved by the Institutional Review Board of Seoul National University Bundang Hospital. The need for informed consent from each patient was waived because the authors did not have access to identifiable information (IRB No: X-19040/535-901).

Study population. We included patients with diagnostic codes for AF from January 2013 to December 2017 and who received DOAC (rivaroxaban, apixaban, dabigatran, or edoxaban) treatment for 7 days or longer from initial diagnosis $(n=3681)$. We used several exclusion criteria to maximize data accuracy. First, we excluded AF patients previously prescribed DOAC between January 2013 and December 2013 to analyze only new cases $(n=1188)$. Second, patients $<20$ years of age diagnosed with AF and patients with valvular AF were excluded $(n=2)$. Third, patients with an alternative indication for DOAC treatment and prophylaxis, including deep vein thrombosis, pulmonary embolism, and joint replacement surgery, were excluded $(n=25)$. Fourth, patients with end-stage renal disease were excluded $(\mathrm{n}=0)$. Lastly, patients with ischemic stroke (IS), intracranial hemorrhage (ICH), or gastrointestinal (GI) bleeding in the 6 months prior to cohort entry were excluded in the analysis of primary prevention $(n=528)$. Finally, a total of 1938 patients (diagnosed between January 2014 and December 2017) were selected for this study. The detailed patient enrollment flow is described in Supplementary Figure 1.

DDIs. Forty-five concurrent medications that may have a potential DDI with DOACs were selected as follows: (1) drugs affecting platelet function such as antiplatelet agents, non-steroidal anti-inflammatory drugs (NSAIDs), and serotonergic agents such as selective serotonin reuptake inhibitors (SSRIs), and serotonin and norepinephrine reuptake inhibitors (SNRIs); (2) P-glycoprotein inhibitors or CYP3A4 inhibitors such as amiodarone, clarithromycin, cobicistat, fluconazole, itraconazole, and voriconazole; and (3) P-glycoprotein inducers or CYP3A4 inducers such as carbamazepine, phenobartibal, phenytoin, and rifampin ${ }^{22-25}$ (Supplementary Table 1).

Study outcomes. We identified four clinical outcomes as follows: IS, ICH, hospitalization for GI bleeding, and hospitalization for major bleeding. To assess the outcomes, we followed up the patients for 1 year. Detailed definitions of the clinical outcomes are described in Supplementary Table 2.

DOACs administered within 30 days before the clinical outcomes were examined to assess clinical outcomes associated with DOACs. If DOACs were not administered within 30 days before the events, the event was not counted in our analysis. To identify potential drug interactions causing an increased risk of DOAC-related bleeding or a reduced antithrombotic efficacy, we examined the use of DDI drugs 30 days prior to the events.

Comorbidities. Comorbidities were included in the model as $\mathrm{CHA}_{2} \mathrm{DS}_{2}$-VASc scores by assigning 1 point for age between 65 and 74 years, female sex, hypertension, diabetes, congestive heart failure, or vascular disease, and adding 2 points for age 75 years or older, history of stroke, transient ischemic attack, or systemic thromboembolism ${ }^{26}$. $\mathrm{CHA}_{2} \mathrm{DS}_{2}$-VASc scores were divided into three categories: $0-1,2-3$, and $\geq 4$.

Statistical methods. Patient characteristics were summarized using descriptive statistics. The median and interquartile range (IQR) was reported for continuous variables, and categorical variables were expressed as frequencies (percentage). Multiple logistic regression analysis was performed using a forced entry method to examine the associations of the $\mathrm{CHA}_{2} \mathrm{DS}_{2}$-VASc score and DDIs with the risk for poor clinical outcomes. For each independent variable, the odds ratio (OR) and $95 \%$ confidence interval (CI) were determined. All tests were 2 -tailed, with $P<0.05$ considered significant. All statistical analysis was performed using R Statistical Software version 3.6.3 (Vienna, Austria; http://www.R-project.org/).

\section{Results}

Baseline characteristics. Between 2014 and 2017, a total of 1,938 patients with AF who were newly administered DOACs were included in the study. The clinical baseline characteristics of the study are shown in Table 1 . The median age was 72 years, and $61.8 \%$ of the patients were males. Among the DOACs, rivaroxaban was the most used (29.4\%), followed by apixaban (22.3\%) and dabigatran (15.2\%). The proportion of subjects in each $\mathrm{CHA}_{2} \mathrm{DS}_{2}$-VASc score category was as follows: $28.2 \%$ in category $0-1,49.4 \%$ in category $2-3$, and $22.4 \%$ in category $\geq 4$.

Ischemic stroke. IS events associated with DOACs occurred in 29 patients (1.5\%) during the observation period (Table 2). Although not statistically significant, the median age was higher in the IS group than in the group without IS (76 vs. 71 years, $P=0.062$ ). The $\mathrm{CHA}_{2} \mathrm{DS}_{2}$-VASc score was significantly associated with IS occurrence; as the score increased, so did the risk of IS. In addition, IS events were more common in patients who simultaneously took drugs with potential DDIs and DOACs, with risk increasing alongside the number of DDIs: $1(\mathrm{OR}=6.22 ; 95 \% \mathrm{CI}, 2.65-15.67, P<0.0001)$ and $\geq 2(\mathrm{OR}=12.22 ; 95 \% \mathrm{CI}, 4.21-34.72, P<0.001)$. The use of P-glycoprotein inducers or CYP3A4 inducers was not observed in patients with IS (Supplementary Table 3). Most of the potential drugs used in patients with IS were identified as pharmacodynamic drugs: antiplatelet agents such as aspirin $(n=15)$ and clopoidogrel $(n=5)$ (Supplementary Table 3). 


\begin{tabular}{|c|c|c|}
\hline & $\mathbf{N}$ & $\%$ \\
\hline \multicolumn{3}{|l|}{ Age, years } \\
\hline Median (IQR) & $72(62-78)$ & \\
\hline$<65$ & 571 & 29.5 \\
\hline $65-74$ & 621 & 32.0 \\
\hline$\geq 75$ & 746 & 38.5 \\
\hline \multicolumn{3}{|l|}{ Sex } \\
\hline Male & 1,198 & 61.8 \\
\hline Female & 740 & 38.2 \\
\hline \multicolumn{3}{|l|}{ DOAC } \\
\hline Rivaroxaban & 569 & 29.4 \\
\hline Apixaban & 433 & 22.3 \\
\hline Dabigatran & 295 & 15.2 \\
\hline Edoxaban & 159 & 8.2 \\
\hline Mixed $^{*}$ & 482 & 24.9 \\
\hline \multicolumn{3}{|c|}{$\mathrm{CHA}_{2} \mathrm{DS}_{2}$-VASc score } \\
\hline $0-1$ & 546 & 28.2 \\
\hline $2-3$ & 957 & 49.4 \\
\hline$\geq 4$ & 435 & 22.4 \\
\hline
\end{tabular}

Table 1. Baseline characteristics of the study population. IQR, interquartile range; DOAC, direct oral anticoagulant. $\mathrm{CHA}_{2} \mathrm{DS}_{2}$-VASc scores indicate congestive heart failure, hypertension, age $\geq 75$ years (doubled), diabetes mellitus, prior stroke or transient ischemic attack (doubled), vascular disease, age 65 to 74 years, and female sex. ${ }^{\star}$ Mixed signifies the patient switched DOACs.

\begin{tabular}{|c|c|c|c|c|c|c|}
\hline & \multicolumn{2}{|c|}{$\begin{array}{l}\text { Ischemic stroke } \\
(\mathrm{N}=29)\end{array}$} & \multicolumn{2}{|c|}{$\begin{array}{l}\text { No ischemic stroke } \\
(\mathrm{N}=1,909)\end{array}$} & \multirow[b]{2}{*}{ Odds ratio $(95 \% \mathrm{CI})$} & \multirow[b]{2}{*}{$P$-value } \\
\hline & $\mathbf{N}$ & $\%$ & $\mathbf{N}$ & $\%$ & & \\
\hline Age, median (IQR) & \multicolumn{2}{|l|}{$76(71-80)$} & \multicolumn{2}{|l|}{$71(62-78)$} & $1.04(1.00-1.08)$ & 0.062 \\
\hline \multicolumn{7}{|l|}{ Sex } \\
\hline Male & 18 & 62.1 & 1,180 & 61.8 & REF & \\
\hline Female & 11 & 37.9 & 729 & 38.2 & $0.99(0.45-2.08)$ & 0.977 \\
\hline \multicolumn{7}{|l|}{$\mathrm{CHA}_{2} \mathrm{DS}_{2}$-VASc } \\
\hline $0-1$ & 4 & 13.8 & 542 & 28.4 & REF & \\
\hline $2-3$ & 10 & 34.5 & 947 & 49.6 & $1.43(0.48-5.24)$ & 0.546 \\
\hline$\geq 4$ & 15 & 51.7 & 420 & 22.0 & $4.84(1.74-17.07)$ & 0.005 \\
\hline \multicolumn{7}{|l|}{ DOAC } \\
\hline Rivaroxaban & 9 & 31.0 & 560 & 29.3 & REF & \\
\hline Apixaban & 1 & 3.5 & 432 & 22.6 & $0.14(0.01-0.77)$ & 0.067 \\
\hline Dabigatran & 1 & 3.5 & 294 & 15.4 & $0.21(0.11-1.13)$ & 0.142 \\
\hline Edoxaban & 1 & 3.5 & 158 & 8.3 & $0.39(0.02-2.12)$ & 0.378 \\
\hline Mixed* & 17 & 58.6 & 465 & 24.4 & $2.28(1.03-5.36)$ & 0.049 \\
\hline \multicolumn{7}{|l|}{ DDI } \\
\hline No & 8 & 27.6 & 1,411 & 73.9 & REF & \\
\hline Yes & 21 & 72.4 & 498 & 26.1 & $7.44(3.40-17.97)$ & $<0.001$ \\
\hline \multicolumn{7}{|l|}{ Number of DDIs } \\
\hline 0 & 8 & 27.6 & 1,411 & 73.9 & REF & \\
\hline 1 & 14 & 48.3 & 397 & 20.8 & $6.22(2.65-15.67)$ & $<0.001$ \\
\hline$\geq 2$ & 7 & 24.1 & 101 & 5.3 & $12.22(4.21-34.72)$ & $<0.001$ \\
\hline
\end{tabular}

Table 2. Comparisons between patients with and without ischemic stroke. IQR, interquartile range; DOAC, direct oral anticoagulant; DDI, drug-drug interaction; REF, reference. $\mathrm{CHA}_{2} \mathrm{DS}_{2}$-VASc score indicates congestive heart failure, hypertension, age $\geq 75$ years (doubled), diabetes mellitus, prior stroke or transient ischemic attack (doubled), vascular disease, age 65 to 74 years, and female sex. ${ }^{\star}$ Mixed signifies the patient switched DOACs. 


\begin{tabular}{|c|c|c|c|c|c|c|}
\hline & \multicolumn{2}{|c|}{$\begin{array}{l}\text { Hospitalization } \\
\text { for major bleeding } \\
(\mathrm{N}=22)\end{array}$} & \multicolumn{2}{|c|}{$\begin{array}{l}\text { No hospitalization } \\
\text { for major bleeding } \\
(\mathrm{N}=1,916)\end{array}$} & \multirow[b]{2}{*}{ Odds ratio $(95 \% \mathrm{CI})$} & \multirow[b]{2}{*}{$P$-value } \\
\hline & $\mathbf{N}$ & $\%$ & $\mathbf{N}$ & $\%$ & & \\
\hline Age, median (IQR) & \multicolumn{2}{|l|}{$81(75-84)$} & \multicolumn{2}{|l|}{$71(62-78)$} & $1.13(1.07-1.19)$ & $<0.001$ \\
\hline \multicolumn{7}{|l|}{ Sex } \\
\hline Male & 13 & 59.1 & 1,185 & 61.9 & REF & \\
\hline Female & 9 & 40.9 & 731 & 38.1 & $1.12(0.46-2.61)$ & 0.791 \\
\hline \multicolumn{7}{|l|}{$\mathrm{CHA}_{2} \mathrm{DS}_{2}-\mathrm{VASc}$} \\
\hline $0-1$ & 1 & 4.6 & 545 & 28.4 & REF & \\
\hline $2-3$ & 12 & 54.5 & 945 & 49.3 & $6.92(1.36-126.26)$ & 0.063 \\
\hline$\geq 4$ & 9 & 40.9 & 426 & 22.2 & $11.51(2.15-212.75)$ & 0.021 \\
\hline \multicolumn{7}{|l|}{ DOAC } \\
\hline Rivaroxaban & 5 & 22.7 & 564 & 29.4 & REF & \\
\hline Apixaban & 7 & 31.8 & 426 & 22.2 & $1.85(0.59-6.30)$ & 0.295 \\
\hline Dabigatran & 1 & 4.6 & 294 & 15.3 & $0.38(0.02-2.39)$ & 0.383 \\
\hline Edoxaban & 0 & 0 & 159 & 8.3 & 0 & 0.986 \\
\hline Mixed $^{*}$ & 9 & 40.9 & 473 & 24.7 & $2.15(0.74-7.03)$ & 0.174 \\
\hline \multicolumn{7}{|l|}{ DDI } \\
\hline No & 11 & 50.0 & 1,413 & 73.8 & REF & \\
\hline Yes & 11 & 50.0 & 503 & 26.2 & $2.81(1.20-6.60)$ & 0.016 \\
\hline \multicolumn{7}{|l|}{ Number of DDIs } \\
\hline 0 & 11 & 50.0 & 1,413 & 73.7 & REF & \\
\hline 1 & 8 & 36.4 & 396 & 20.7 & $2.60(1.00-6.46)$ & 0.042 \\
\hline$\geq 2$ & 3 & 13.6 & 107 & 5.6 & $3.60(0.81-11.7)$ & 0.052 \\
\hline
\end{tabular}

Table 3. Comparisons between patients with and without hospitalization for major bleeding. IQR, interquartile range; DOAC, direct oral anticoagulant; DDI, drug-drug interaction; REF, reference. $\mathrm{CHA}_{2} \mathrm{DS}_{2}$ VASc indicates congestive heart failure, hypertension, age $\geq 75$ years (doubled), diabetes mellitus, prior stroke or transient ischemic attack (doubled), vascular disease, age 65 to 74 years, and female sex. ${ }^{*}$ Mixed signifies the patient switched DOACs.

Hospitalization for major bleeding. Hospitalization for major bleeding associated with the use of DOACs occurred in 22 patients (1.1\%) during the observation period (Table 3 ). The median age was significantly higher in the hospitalization for major bleeding group than in the group without hospitalization for major bleeding ( 81 vs. 71 years, $P<0.001)$. When analyzed against the $\mathrm{CHA}_{2} \mathrm{DS}_{2}$-VASc score, events of hospitalization for major bleeding were significantly more likely patients with 4 points or more compared to patients with $0-1$ points $(\mathrm{OR}=11.51 ; 95 \% \mathrm{CI}, 2.15-212.75, P=0.021)$. There was no association between DOAC type and hospitalization for major bleeding events. Hospitalization for major bleeding events had a statistically significant relationship with potential DDIs $(\mathrm{OR}=2.81 ; 95 \% \mathrm{CI}, 1.20-6.60, P=0.016)$, and the risk tended to increase as the number of DDIs increased. Most of the potential drugs used in patients with hospitalization for major bleeding were antiplatelet agents $(n=4)$ or NSAIDs $(n=3)$ (Supplementary Table 4). The relationship between ICH and hospitalization for GI bleeding and DDI is described in Supplementary Tables 5 and 6, respectively. GI bleeding showed a statistically significant relationship with DDI, whereas ICH did not.

Multiple logistic regression analysis for clinical outcomes. Multiple logistic regression analysis showed that increased risk of IS and hospitalization for major bleeding was associated with the number of DDIs regardless of comorbidities: $\geq 2$ DDIs was associated with IS (OR $=18.68$; 95\% CI, 6.22-55.27, $P<0.001)$ and hospitalization for major bleeding $(\mathrm{OR}=5.01$; 95\% CI, 1.11-16.62, $P<0.001)$ (Table 4).

\section{Discussion}

Management of oral anticoagulant drug interaction is essential to ensure safe and effective use. Warfarin has over 200 identified drug interactions that must be considered before use ${ }^{27}$. Wang et al. conducted meta-analysis based on low- to moderate-strength evidence supporting interaction between warfarin and a small group of medications leading to bleeding risk or thromboembolic outcomes ${ }^{28}$. Although DOACs have comparable efficacy and enhanced safety compared to warfarin, the appropriateness and accuracy of prescribing medications are important to prevent increased risk of bleeding or reduced antithrombotic efficacy. In the current study, we found that potential DDIs were associated with a substantially high risk for both ischemic stroke and hospitalization for major bleeding regardless of comorbidities.

Drug interactions have been previously associated with decreased potency of DOACs ${ }^{25}$. Based on pharmacokinetic data and published case reports, there is a significant decrease in DOAC drug concentration and an increased risk of adverse thrombotic events in patients receiving concomitant P-glycoprotein inducers or CYP3A4 inducers ${ }^{29-32}$. DDIs were associated with a significantly higher risk for IS, in particular for DDIs with $\geq 2$ 


\begin{tabular}{|c|c|c|c|c|}
\hline \multirow[b]{2}{*}{ Variables } & \multicolumn{2}{|l|}{ Ischemic stroke } & \multicolumn{2}{|c|}{ Hospitalization for major bleeding } \\
\hline & Odds ratio $(95 \% \mathrm{CI})$ & $P$ value & Odds ratio $(95 \% \mathrm{CI})$ & $P$ value \\
\hline \multicolumn{5}{|c|}{$\mathrm{CHA}_{2} \mathrm{DS}_{2}$-VASc } \\
\hline $0-1$ & REF & & REF & \\
\hline $2-3$ & $2.35(0.77-8.71)$ & 0.157 & $9.42(1.82-172.79)$ & 0.032 \\
\hline$\geq 4$ & $8.27(2.87-30.03)$ & $<0.001$ & $15.09(2.78-280.42)$ & 0.011 \\
\hline \multicolumn{5}{|c|}{ Number of DDIs } \\
\hline 0 & REF & & REF & \\
\hline 1 & $6.92(2.91-17.61)$ & $<0.001$ & $3.27(1.25-8.21)$ & 0.012 \\
\hline$\geq 2$ & $18.68(6.22-55.27)$ & $<0.001$ & $5.01(1.11-16.62)$ & 0.016 \\
\hline
\end{tabular}

Table 4. Multiple logistic regression analysis for clinical outcomes. DDI, drug-drug interaction; REF, reference. $\mathrm{CHA}_{2} \mathrm{DS}_{2}$-VASc indicates congestive heart failure, hypertension, age $\geq 75$ years (doubled), diabetes mellitus, prior stroke or transient ischemic attack (doubled), vascular disease, age 65 to 74 years, and female sex.

prescribed drugs (OR, 18.68; 95\% CI, 6.22-55.27). Most of the DDIs related to IS were pharmacodynamic drugs such as antiplatelet agents or NSAIDs and were not related to P-glycoprotein inducers or CYP3A4 inducers. The ARISTOTLE trial reported that participants on aspirin were at higher risk for ischemic events, with higher $\mathrm{CHADS}_{2}$ scores, than were participants not receiving aspirin ${ }^{33}$. In the current study, concomitant use of antiplatelet agents was observed in patients with IS, which could explain the higher $\mathrm{CHA}_{2} \mathrm{DS}_{2}$-VASc scores of those on antiplatelet agents. Previous studies demonstrated a thrombotic risk associated with NSAIDs ${ }^{34-36}$. Kent et al. demonstrated that the use of NSAIDs was associated with an increased risk for ischemic stroke as well as major bleeding ${ }^{37}$. It is difficult to assess the clinical relevance of DOAC drug interactions because the available data are frequently limited to pharmacokinetic studies in a small number of healthy volunteers or retrospective case-control or cohort studies.

Romoli et al. showed that switching between DOACs is frequent, occurring in up to $11 \%$ of patients prescribed with DOAC for AF. In this study, one in 4 patients had to switch between DOACs within 30 days before ischemic stroke or bleeding events. Due to the anonymization of CDM data, the cause of switching between DOACs was not known, but other studies reported that minor bleeding and non-CV adverse events had been reported as one of the most common causes to justify switching between DOACs ${ }^{38,39}$. IS was more common in those who changed DOACs compared to those who took rivaroxaban alone, with an OR of 2.28. Considering that continuous adherence to DOACs is essential to maintain stroke risk reduction ${ }^{40,41}$, the inability to take continuous doses could result in IS events.

In the current study, among those hospitalized for major bleeding, GI bleeding showed a statistically significant relationship with DDIs, but ICH did not. Our group reported that the rate of exposure to DDIs in bleeding events was about $57 \%$, and NSAIDs and antiplatelet agents were the most common drugs for DDIs ${ }^{17}$. Although the data is not presented in this study, NSAIDs and antiplatelet agents caused potential DDIs as their use alongside DOACs was concomitant when GI bleeding occurred. The combination of anticoagulation medication and NSAIDs or aspirin increased the risk of GI bleeding ${ }^{42,43}$. The mechanism for the increased GI bleeding associated with NSAIDs relies on the effect of NSAIDs on platelet aggregation and gastric mucosa ${ }^{44,45}$. In addition, considering the potential renal effect of NSAIDs, it is possible that the exposure increased in the concomitant with DOACs, which are mainly excreted by the kidney ${ }^{46}$.

Our study has several limitations. First, due to the nature of the CDM data, we could not review the medical records of any individual patient such as lifestyle risk factors like cigarette smoking and alcohol consumption or change of DOACs due to serious side effects. Second, according to the recent domestic claim data, less than $10 \%$ of AF patients using DOAC had $\mathrm{CHA}_{2} \mathrm{DS}_{2}$-VASc scores of $0-1{ }^{17,47}$, but the current CDM study showed that proportion to be close to $28 \%$. The reason for the higher proportion of patients with CHA2DS2-VASc scores of 0-1 compared to other studies is that the diagnosis of comorbidities such as hypertension and diabetes are likely to be missed. To correct this error, even if there was no diagnosis, CHA2DS2-VASc scores reflected whether a patient was taking medication for hypertension or diabetes. Third, the CDM database did not have data on adherence to prescribed medications and information on other hospital medications. In Korea, there is a Korean Health Insurance Review and Assessment Service database to check the history of drug administration while visiting a hospital for the last 90 days. In the future, the limitations of the CDM database can be overcome by reflecting this information. Fourth, as with all non-experimental studies, associations can be drawn, but causality can only be inferred. The number of DDIs can either decrease or enhance the effect of the involved drugs, increasing the risk of side-effects, as well as indicate the presence of multimorbidity. Further studies are required to better understand DDIs leading to adverse events in patients with polypharmacy. Lastly, the potential DDIs of this study may contain inaccuracies or contradict other interaction databases. In light of these limitations, it is essential to regularly reassess the literature for optimal clinical decision-making.

In conclusion, physicians prescribing DOACs for AF should be aware that DDIs can cause significantly increased risk for both IS and hospitalization for major bleeding regardless of comorbidities. 
Received: 20 May 2021; Accepted: 19 October 2021

Published online: 17 November 2021

\section{References}

1. Rahman, F., Kwan, G. F. \& Benjamin, E. J. Global epidemiology of atrial fibrillation. Nat. Rev. Cardiol. 11, 639-654. https://doi. org/10.1038/nrcardio.2014.118 (2014).

2. Schnabel, R. B. et al. 50 year trends in atrial fibrillation prevalence, incidence, risk factors, and mortality in the Framingham Heart Study: a cohort study. Lancet 386, 154-162. https://doi.org/10.1016/s0140-6736(14)61774-8 (2015).

3. Wolf, P. A., Abbott, R. D. \& Kannel, W. B. Atrial fibrillation as an independent risk factor for stroke: the Framingham Study. Stroke 22, 983-988. https://doi.org/10.1161/01.str.22.8.983 (1991).

4. Wolf, P. A., Abbott, R. D. \& Kannel, W. B. Atrial fibrillation: a major contributor to stroke in the elderly. The Framingham Study. Arch. Intern. Med. 147, 1561-1564 (1987).

5. Connolly, S. J. et al. Dabigatran versus warfarin in patients with atrial fibrillation. N. Engl. J. Med. 361, 1139-1151. https://doi.org/ 10.1056/NEJMoa0905561 (2009).

6. Patel, M. R. et al. Rivaroxaban versus warfarin in nonvalvular atrial fibrillation. N. Engl. J. Med. 365, 883-891. https://doi.org/10. 1056/NEJMoa1009638 (2011).

7. Granger, C. B. et al. Apixaban versus warfarin in patients with atrial fibrillation. N. Engl. J. Med. 365, 981-992. https://doi.org/10. 1056/NEJMoa1107039 (2011).

8. Giugliano, R. P. et al. Edoxaban versus warfarin in patients with atrial fibrillation. N. Engl. J. Med. 369, 2093-2104. https://doi.org/ 10.1056/NEJMoa1310907 (2013)

9. Kirchhof, P. et al. 2016 ESC Guidelines for the management of atrial fibrillation developed in collaboration with EACTS. Eur. Heart J. 37, 2893-2962. https://doi.org/10.1093/eurheartj/ehw210 (2016).

10. Tellor, K. B., Patel, S., Armbruster, A. L. \& Daly, M. W. Evaluation of the appropriateness of dosing, indication and safety of rivaroxaban in a community hospital. J. Clin. Pharm. Ther. 40, 447-451. https://doi.org/10.1111/jcpt.12288 (2015).

11. Armbruster, A. L., Buehler, K. S., Min, S. H., Riley, M. \& Daly, M. W. Evaluation of dabigatran for appropriateness of use and bleeding events in a community hospital setting. Am. Health Drug Benefits 7, 376-384 (2014).

12. Spinewine, A. et al. Appropriate prescribing in elderly people: how well can it be measured and optimised?. Lancet 370, 173-184. https://doi.org/10.1016/s0140-6736(07)61091-5 (2007).

13. Proietti, M., Raparelli, V., Olshansky, B. \& Lip, G. Y. Polypharmacy and major adverse events in atrial fibrillation: observations from the AFFIRM trial. Clin. Res. Cardiol. 105, 412-420. https://doi.org/10.1007/s00392-015-0936-y (2016).

14. Piccini, J. P. et al. Polypharmacy and the efficacy and safety of rivaroxaban versus warfarin in the prevention of stroke in patients with nonvalvular atrial fibrillation. Circulation 133, 352-360. https://doi.org/10.1161/circulationaha.115.018544 (2016).

15. Jaspers Focks, J. et al. Polypharmacy and effects of apixaban versus warfarin in patients with atrial fibrillation: post hoc analysis of the ARISTOTLE trial. BMJ 353, i2868. https://doi.org/10.1136/bmj.i2868 (2016).

16. Momo, K. et al. Prevalence of drug-drug interaction in atrial fibrillation patients based on a large claims data. PLoS ONE 14, e0225297. https://doi.org/10.1371/journal.pone.0225297 (2019).

17. Lee, J. Y. et al. The increased risk of bleeding due to drug-drug interactions in patients administered direct oral anticoagulants. Thromb. Res. 195, 243-249. https://doi.org/10.1016/j.thromres.2020.07.054 (2020).

18. Hripcsak, G. et al. Observational health data sciences and informatics (OHDSI): opportunities for observational researchers. Stud. Health Technol. Inform. 216, 574-578 (2015).

19. Overhage, J. M., Ryan, P. B., Reich, C. G., Hartzema, A. G. \& Stang, P. E. Validation of a common data model for active safety surveillance research. J. Am. Med. Inform. Assoc. 19, 54-60. https://doi.org/10.1136/amiajnl-2011-000376 (2012).

20. Kim, H. et al. Characterization of anti-seizure medication treatment pathways in pediatric epilepsy using the electronic health record-based common data model. Front. Neurol. 11, 409. https://doi.org/10.3389/fneur.2020.00409 (2020).

21. Choi, S. A. et al. Analysis of antiseizure drug-related adverse reactions from the electronic health record using the common data model. Epilepsia 61, 610-616. https://doi.org/10.1111/epi.16472 (2020).

22. Heidbuchel, H. et al. EHRA practical guide on the use of new oral anticoagulants in patients with non-valvular atrial fibrillation: executive summary. Eur. Heart J. 34, 2094-2106. https://doi.org/10.1093/eurheartj/eht134 (2013).

23. Heidbuchel, H. et al. Updated European Heart Rhythm Association practical guide on the use of non-vitamin-K antagonist anticoagulants in patients with non-valvular atrial fibrillation: executive summary. Eur. Heart J. 38, 2137-2149. https://doi.org/10. 1093/eurheartj/ehw058 (2017).

24. Stöllberger, C. Drug interactions with new oral anticoagulants in elderly patients. Exp. Rev. Clin. Pharmacol. 10, 1191-1202. https:// doi.org/10.1080/17512433.2017.1370369 (2017).

25. Vazquez, S. R. Drug-drug interactions in an era of multiple anticoagulants: a focus on clinically relevant drug interactions. Blood 132, 2230-2239. https://doi.org/10.1182/blood-2018-06-848747 (2018).

26. Lip, G. Y., Nieuwlaat, R., Pisters, R., Lane, D. A. \& Crijns, H. J. Refining clinical risk stratification for predicting stroke and thromboembolism in atrial fibrillation using a novel risk factor-based approach: the euro heart survey on atrial fibrillation. Chest 137, 263-272. https://doi.org/10.1378/chest.09-1584 (2010).

27. Nutescu, E., Chuatrisorn, I. \& Hellenbart, E. Drug and dietary interactions of warfarin and novel oral anticoagulants: an update. J. Thromb Thrombolysis 31, 326-343. https://doi.org/10.1007/s11239-011-0561-1 (2011).

28. Wang, M. et al. Drug-drug interactions with Warfarin: a systematic review and meta-analysis. Br. J. Clin. Pharmacol. https://doi. org/10.1111/bcp.14833(2021).

29. Burnett, A. E. et al. Guidance for the practical management of the direct oral anticoagulants (DOACs) in VTE treatment. J. Thromb Thrombolysis 41, 206-232. https://doi.org/10.1007/s11239-015-1310-7 (2016).

30. Steffel, J. et al. The 2018 European heart rhythm association practical guide on the use of non-vitamin K antagonist oral anticoagulants in patients with atrial fibrillation: executive summary. Europace 20, 1231-1242. https://doi.org/10.1093/europace/euy054 (2018).

31. Wiggins, B. S., Northup, A., Johnson, D. \& Senfield, J. Reduced anticoagulant effect of dabigatran in a patient receiving concomitant phenytoin. Pharmacotherapy 36, e5-7. https://doi.org/10.1002/phar.1698 (2016).

32. Stöllberger, C. \& Finsterer, J. Recurrent venous thrombosis under rivaroxaban and carbamazepine for symptomatic epilepsy. Neurol. Neurochir. Pol. 51, 194-196. https://doi.org/10.1016/j.pjnns.2017.01.010 (2017).

33. Kumar, S. et al. Non-vitamin K antagonist oral anticoagulants and antiplatelet therapy for stroke prevention in patients with atrial fibrillation: a meta-analysis of randomized controlled trials. Cardiol. Rev. 24, 218-223. https://doi.org/10.1097/crd.0000000000 000088 (2016).

34. Chang, C. H., Shau, W. Y., Kuo, C. W., Chen, S. T. \& Lai, M. S. Increased risk of stroke associated with nonsteroidal anti-inflammatory drugs: a nationwide case-crossover study. Stroke 41, 1884-1890. https://doi.org/10.1161/strokeaha.110.585828 (2010).

35. Fosbøl, E. L. et al. Use of nonsteroidal anti-inflammatory drugs among healthy people and specific cerebrovascular safety. Int. J. Stroke 9, 943-945. https://doi.org/10.1111/j.1747-4949.2012.00863.x (2014). 
36. Lamberts, M. et al. Relation of nonsteroidal anti-inflammatory drugs to serious bleeding and thromboembolism risk in patients with atrial fibrillation receiving antithrombotic therapy: a nationwide cohort study. Ann. Intern. Med. 161, 690-698. https://doi. org/10.7326/m13-1581 (2014).

37. Kent, A. P. et al. Concomitant oral anticoagulant and nonsteroidal anti-inflammatory drug therapy in patients with atrial fibrillation. J. Am. Coll. Cardiol. 72, 255-267. https://doi.org/10.1016/j.jacc.2018.04.063 (2018).

38. Hellfritzsch, M. et al. Clinical events preceding switching and discontinuation of oral anticoagulant treatment in patients with atrial fibrillation. Europace 19, 1091-1095. https://doi.org/10.1093/europace/euw241 (2017).

39. Marchetti, G., Bernardini, F., Romoli, M. \& Urbinati, S. Switching across direct oral anticoagulants: a real-life-setting pilot prospective study. J. Cardiovasc. Med. (Hagerstown) https://doi.org/10.2459/jcm.0000000000001118 (2020).

40. Borne, R. T. et al. Adherence and outcomes to direct oral anticoagulants among patients with atrial fibrillation: findings from the veterans health administration. BMC Cardiovasc. Disord. 17, 236. https://doi.org/10.1186/s12872-017-0671-6 (2017)

41. Yao, X. et al. Effect of adherence to oral anticoagulants on risk of stroke and major bleeding among patients with atrial fibrillation. J. Am. Heart Assoc. 5, doi:https://doi.org/10.1161/jaha.115.003074 (2016).

42. Battistella, M., Mamdami, M. M., Juurlink, D. N., Rabeneck, L. \& Laupacis, A. Risk of upper gastrointestinal hemorrhage in warfarin users treated with nonselective NSAIDs or COX-2 inhibitors. Arch. Intern. Med. 165, 189-192. https://doi.org/10.1001/archinte. 165.2.189 (2005).

43. Davidson, B. L. et al. Bleeding risk of patients with acute venous thromboembolism taking nonsteroidal anti-inflammatory drugs or aspirin. JAMA Intern. Med. 174, 947-953. https://doi.org/10.1001/jamainternmed.2014.946 (2014).

44. Schafer, A. I. Effects of nonsteroidal antiinflammatory drugs on platelet function and systemic hemostasis. J. Clin. Pharmacol. 35, 209-219. https://doi.org/10.1002/j.1552-4604.1995.tb04050.x (1995).

45. Wallace, J. L. How do NSAIDs cause ulcer disease?. Baillieres Best Pract. Res. Clin. Gastroenterol. 14, 147-159. https://doi.org/10. 1053/bega.1999.0065 (2000).

46. Harirforoosh, S. \& Jamali, F. Renal adverse effects of nonsteroidal anti-inflammatory drugs. Exp. Opin. Drug Saf. 8, 669-681. https://doi.org/10.1517/14740330903311023 (2009).

47. Lee, S. R. et al. Oral anticoagulation in asian patients with atrial fibrillation and a history of intracranial hemorrhage. Stroke 51, 416-423. https://doi.org/10.1161/strokeaha.119.028030 (2020).

\section{Author contributions}

J.Y.L. and S.M.B. conceived of the study. I.Y.O., J.H.L., S.K., J.C., C.H.P., and S.Y. conducted the experiments, data analysis, and critical discussions of the results. All authors contributed to the writing and editing of the manuscript and approved the final draft of the manuscript.

\section{Funding}

This research was supported by the Seoul National University Bundang Hospital Research Fund (14-2020039), and the Technology Innovation Program (20004927, 'Upgrade of CDM based Distributed Biohealth Data Platform and Development of Verification Technology') funded By the Ministry of Trade, Industry \& Energy (MOTIE, Korea).

\section{Competing interests}

The authors declare no competing interests.

\section{Additional information}

Supplementary Information The online version contains supplementary material available at https://doi.org/ 10.1038/s41598-021-01786-2.

Correspondence and requests for materials should be addressed to S.-M.B.

Reprints and permissions information is available at www.nature.com/reprints.

Publisher's note Springer Nature remains neutral with regard to jurisdictional claims in published maps and institutional affiliations.

(c) (i) Open Access This article is licensed under a Creative Commons Attribution 4.0 International License, which permits use, sharing, adaptation, distribution and reproduction in any medium or format, as long as you give appropriate credit to the original author(s) and the source, provide a link to the Creative Commons licence, and indicate if changes were made. The images or other third party material in this article are included in the article's Creative Commons licence, unless indicated otherwise in a credit line to the material. If material is not included in the article's Creative Commons licence and your intended use is not permitted by statutory regulation or exceeds the permitted use, you will need to obtain permission directly from the copyright holder. To view a copy of this licence, visit http://creativecommons.org/licenses/by/4.0/.

(C) The Author(s) 2021 